\title{
EMPREENDEDORISMO SUSTENTÁVEL: PROPOSIÇÃO DE UMA TIPOLOGIA E SUGESTÕES DE PESQUISA
}

\author{
Cândido Borges - FACE/UFG \\ Marcos Martins Borges - Faculdade de Tecnologia Senac Goiás ${ }^{2}$ \\ Vicente da Rocha Soares Ferreira - FACE/UFG ${ }^{3}$ \\ Estela Najberg - FACE/UFG \\ Marcelo Ferreira Tete - FACE/UFG ${ }^{5}$
}

Resumo: O presente artigo tem como objetivo propor uma tipologia das diferentes categorias de empreendedorismo sustentável, levantando seus aspectos ainda pouco conhecidos e que poderiam ser explorados em novas pesquisas. Para a construção desta tipologia foi feita uma revisão da literatura sobre empreendedorismo sustentável. A tipologia proposta leva em conta três indicadores: (i) o nicho de negócio explorado (ambiental ou social), (ii) a motivação da incorporação da sustentabilidade (meio ou objetivo) e (iii) a utilização ou não dos pressupostos da responsabilidade social empresarial na empresa nascente. $O$ primeiro indicador considera se é explorado um negócio ambiental ou social. Os negócios ambientais foram classificados em quatro categorias principais: (i) produtos eco eficientes, (ii) turismo e lazer na natureza, (iii) agricultura orgânica e extrativismo e (iv) reciclagem e reutilização. Os negócios sociais foram classificados em quatro categorias principais: (i) produtos para grupos com necessidades especiais, (ii) microcrédito, (iii) comércio justo e (iv) negócios na base da pirâmide. O segundo indicador está relacionado com a motivação para a incorporação da sustentabilidade e se ela é o objetivo do empreendedor ao criar o negócio, ou apenas um meio utilizado para realizar ganhos financeiros. O terceiro indicador trata da utilização ou não dos pressupostos da responsabilidade social empresarial na empresa nascente.

Palavras-chave: Empreendedorismo Sustentável; Eco empreendedorismo; Sustentabilidade; Criação de Empresas Sustentáveis.

\section{SUSTAINABLE ENTREPRENEURSHIP: PROPOSITION OF A TYPOLOGY AND RESEARCH SUGGESTIONS}

Abstract: This article aims to propose a typology of the different categories of sustainable entrepreneurship, raising theirs aspects which is still little known and that could be explored in further researches. For the construction of this typology was made a review of the literature on sustainable entrepreneurship. The proposed typology considers three indicators: (i) the niche of explored business (environmental

\footnotetext{
${ }^{1}$ E mail: candidoborges@gmail.com. Endereço: Campus II - Samambaia - CXP: 131 - CEP 74001970, Goiânia-GO

2 E mail: mborges@nativa.tur.br

${ }^{3}$ E mail: vicenterochasf@uol.com.br

${ }^{4}$ E mail: estelanajberg@gmail.com

${ }^{5}$ E mail: mftete2003@yahoo.com.br
}

BORGES, C.; BORGES, M. M.; FERREIRA, V. R. S.; NAJBERG, E.; TETE, M. F. Empreendedorismo Sustentável: Proposição De Uma Tipologia E Sugestões De Pesquisa. Revista de Empreendedorismo e Gestão de Pequenas Empresas, v. 2, n.1, p. 77-100, 2013. 
or social), (ii) the motivation of the sustainability venture (means or goal) and (iii) the use or not of the assumptions of business social responsibility in the fledgling company. The first indicator considers whether it is explored a social or environmental business. The environmental businesses were classified into four main categories: (i) eco-efficient products, (ii) tourism and recreation in nature, (iii) organic farming and harvesting, and (iv) recycling and reutilization. The social businesses were classified into four main categories: (i) products for groups with special needs, (ii) microcredit, (iii) fair trade and (iv) businesses at the base of the pyramid. The second indicator is related to the motivation for the sustainability incorporation, if it is the goal of entrepreneur in creating the business, or just a means used to achieve financial gain. The third indicator is about the use or not of the assumptions of business social responsibility in the fledgling company.

Keywords: Sustainable Entrepreneurship; Ecoentrepreneurship; Sustainability; Creation of Sustainable Enterprises.

\section{Introdução}

Até a primeira metade do século $\mathrm{XX}$, as empresas surgiam e se expandiam sem grandes preocupações com os impactos ambientais e sociais gerados. $\mathrm{O}$ progresso era visto como consequência de crescimento e desenvolvimento econômico. A ampliação dos mercados consumidores e do número de empresas gerou um aumento na geração de resíduos e no consumo de matéria-prima, tudo isso em um contexto no qual reinava a percepção de que os recursos naturais e a capacidade de absorção da poluição pelo planeta eram infinitos.

Somente a partir da década de 1960, passou-se a questionar o modelo de desenvolvimento vigente e dos impactos sociais e ambientais. As preocupações e discussões foram iniciadas, mesmo que de forma incipiente, sobre a viabilidade de empreendimentos mantidos nos padrões de consumo intensivo em matérias-primas e seus impactos no ambiente e na sociedade. Essa preocupação surgida nos anos 60 teve alguns frutos como, por exemplo, a Conferência de Estocolmo realizada em 1972, que marcou o início dos debates sobre as preocupações mundiais relativas às questões ecológicas. Em 1987 é lançado o documento "Our common future" (Nosso Futuro Comum) como resultado dos trabalhos da Comissão Mundial sobre Meio Ambiente e Desenvolvimento (CMMAD), na qual surge o conceito de desenvolvimento sustentável (SCOTTO; CARVALHO; GUIMARÃES, 2007).

BORGES, C.; BORGES, M. M.; FERREIRA, V. R. S.; NAJBERG, E.; TETE, M. F. Empreendedorismo Sustentável: Proposição De Uma Tipologia E Sugestões De Pesquisa. Revista de Empreendedorismo e Gestão de Pequenas Empresas, v. 2, n.1, p. 77-100, 2013. 
O desenvolvimento sustentável procura integrar o tripé social-econômicoambiental (triple bottom line), harmonizando rentabilidade financeira e crescimento econômico com a justiça, o bem-estar social, a conservação ambiental e a utilização racional dos recursos naturais (SACHS, 1994). Com base nesses movimentos mundiais, toma corpo a discussão sobre a necessidade de mudança das organizações. Temas como gestão ambiental e responsabilidade social empresarial passam a ocupar de forma crescente a agenda dos administradores. Nessa linha, procura-se transformar organizações tradicionais em organizações sustentáveis (BARBIERE; SIMANTON, 2007; LAWRENCE; WEBER; POST, 2005).

Nesse contexto, o empreendedorismo, que sempre foi visto como um agente de transformação social, em especial para 0 crescimento econômico (SCHUMPETER, 1934), passou a ser considerado também como um veículo que pode colaborar para o desenvolvimento sustentável (DEAN; MCMULLEN, 2007; KUCKERTZ; WAGNER, 2010). O empreendedorismo sustentável, que é a descoberta, desenvolvimento e exploração de oportunidades ligadas aos nichos sociais e ambientais que geram ganho econômico e melhoria social ou ambiental (HOCKERTS; WUSTENHAGEN, 2010; SHEPHERD; PATZELT, 2011), está, dessa forma, atraindo a atenção de governos, empreendedores e pesquisadores.

$\mathrm{Na}$ perspectiva das políticas públicas, o empreendedorismo sustentável é visto como um dos meios de se viabilizar o equilíbrio entre o desenvolvimento econômico, ambiental e social de cidades e regiões (GIBBS, 2009; PARRISH; FOXON, 2009). Isto é, uma indústria a ser explorada com grande potencial de criação de empregos (WORLD WIDE FUND FOR NATURE [WWF], 2009) e também o veículo que pode realizar as inovações necessárias para a solução de problemas ambientais e sociais que afligem a humanidade e seu meio ambiente (LARSON, 2000).

$\mathrm{Na}$ perspectiva dos empreendedores, o empreendedorismo sustentável apresenta potencial de maximizar lucros na exploração de oportunidades de negócio ligadas ao nicho ambiental ou social (COHEN; WINN, 2007), ou a possibilidade de colaborar com seu ambiente ou comunidade (PARRISH, 2010). Finalmente, para os

BORGES, C.; BORGES, M. M.; FERREIRA, V. R. S.; NAJBERG, E.; TETE, M. F. Empreendedorismo Sustentável: Proposição De Uma Tipologia E Sugestões De Pesquisa. Revista de Empreendedorismo e Gestão de Pequenas Empresas, v. 2, n.1, p. 77-100, 2013. 
pesquisadores o empreendedorismo sustentável representa um novo segmento do empreendedorismo (SHEPHERD; PATZELT, 2011). Assim como 0 empreendedorismo por mulheres (BRUIN; BRUSH; WELTER, 2007; MACHADO et al., 2003) ou tecnológico (SHANE, 2001) são subáreas do empreendedorismo que desenvolveram um conjunto de conhecimentos específicos, o empreendedorismo sustentável tende a seguir o mesmo caminho, constituindo-se em uma nova subárea (HALL; DANEKE; LENOX, 2010).

Apesar deste potencial e de sua importância, os trabalhos publicados sobre empreendedorismo sustentável ainda são poucos. Nas duas principais revistas científicas dedicadas ao empreendedorismo, por exemplo, até 2009 nenhum artigo foi publicado na Entrepreneurship Theory and Practice (ET\&P) e apenas dois (COHEN e WINN, 2007; DEAN e MCMULLEN, 2007) no Journal of Business Venturing (JBV). Após 2009, um número da JBV foi dedicado ao tema (vol. 25, n. 5, de 2010) e dois artigos publicados na ET\&P (PATZELT; SHEPHERD, 2011; SHEPHERD; PATZELT, 2011), mostrando como é recente o desenvolvimento do conceito. Os estudos sobre empreendedorismo social (ZAHRA et al., 2009) e o empreendedorismo ambiental (SCHAPER, 2002) começaram a ser desenvolvidos antes e podem ser considerados como percussores do empreendedorismo sustentável (HOCKERTS; WUSTENHAGEN, 2010). Essa origem de caminhos próximos, mas não iguais (social e ambiental), em conjunto com o desenvolvimento ainda embrionário de empreendedorismo sustentável geram dificuldades na delimitação do tema e lacunas de pesquisa a serem exploradas.

No intuito de aprofundar a discussão desse tema, o presente artigo tem como objetivo propor uma tipologia com as diferentes categorias de empreendedorismo sustentável, levantando seus aspectos ainda pouco conhecidos, mas que poderiam ser explorados em novas pesquisas.

A criação de tipologias é uma estratégia utilizada em estudos organizacionais (MILES; SNOW; 1986; MILLER, 1996) e em empreendedorismo (PIRNAY; SURLEMONT; NLEMVO, 2003) com objetivo de organizar e classificar um objeto de estudo segundo certas características. A tipologia aqui proposta levará em conta três

BORGES, C.; BORGES, M. M.; FERREIRA, V. R. S.; NAJBERG, E.; TETE, M. F. Empreendedorismo Sustentável: Proposição De Uma Tipologia E Sugestões De Pesquisa. Revista de Empreendedorismo e Gestão de Pequenas Empresas, v. 2, n.1, p. 77-100, 2013. 
indicadores: (i) o nicho de negócio explorado (ambiental ou social), (ii) a motivação da incorporação da sustentabilidade (meio ou objetivo) e (iii) a utilização ou não dos pressupostos da responsabilidade social empresarial na empresa nascente.

Para a construção desta tipologia, foi feita uma revisão da literatura sobre empreendedorismo sustentável. Entre as diferentes perspectivas do empreendedorismo, este artigo foca na criação de novas empresas (GARTNER, 1985), não fazendo parte do seu escopo o empreendedorismo corporativo (DESS et al., 2003; MILES; MUNILLA; DARROCH, 2009). Serão abordados dessa forma, os aspectos da sustentabilidade na fase inicial da organização.

O artigo está estruturado da seguinte forma: a próxima seção será dedicada à origem do conceito de empreendedorismo sustentável e estabelecerá a base da construção da tipologia. As seções três, quatro e cinco são dedicadas aos três indicadores utilizados na tipologia. A seção seis finaliza 0 artigo e indica oportunidades de pesquisa.

\section{Empreendedorismo Sustentável}

Como se há de verificar, os estudos em empreendedorismo sustentável têm ligação com duas outras áreas do empreendedorismo: o social e o ambiental. Foi na comunidade que estudava e militava a causa ambiental que o empreendedorismo ambiental apareceu como objeto de estudo e de interesse, mesmo antes de surgir no campo do empreendedorismo (HALL; DANEKE; LENOX, 2010). Trabalhos nessa área foram inicialmente publicados mais em revistas científicas da área de gestão ambiental, como o Greener Management International (PASTAKIA, 2002) e o Society and Natural Resources (ALLEN; MALIN, 2008). Vale ressaltar que os autores eram de áreas fora do campo do empreendedorismo. Só recentemente as revistas de maior impacto em empreendedorismo abriram espaço para o tema. Além de empreendedorismo ambiental (HOLT, 2011), a literatura usa outros termos para se referir à interseção entre empreendedorismo e meio ambiente: ecoempreendedorismo (SCHALTEGGER, 2002; BENNETT, 1991),

BORGES, C.; BORGES, M. M.; FERREIRA, V. R. S.; NAJBERG, E.; TETE, M. F. Empreendedorismo Sustentável: Proposição De Uma Tipologia E Sugestões De Pesquisa. Revista de Empreendedorismo e Gestão de Pequenas Empresas, v. 2, n.1, p. 77-100, 2013. 
empreendedorismo verde (ALLEN; MALIN, 2008) ou enviropreneurship (MENON; MENON, 1997).

O empreendedorismo social aparece de forma mais presente e institucionalizada no campo do empreendedorismo do que o empreendedorismo ambiental. Prova disso é que já em 2002, o Frontiers of Entrepreneurship Research, que são os anais da conferência da Babson, um dos mais importantes eventos científicos sobre empreendedorismo, reservavam uma seção para o empreendedorismo social. Inicialmente intitulada de "Non-profit", em 2004 essa seção passou a ser chamada de "Social" e desde 2006, "Social Entrepreneurship". Até o presente momento, Babson não criou uma seção para o empreendedorismo ambiental, nem para o sustentável.

Apesar de mais presente nas publicações científicas do campo do empreendedorismo, o empreendedorismo social aparece menos nas pesquisas que tratam de empreendedorismo sustentável. Exemplo disso é o trabalho de Hall, Daneke e Lenox (2010), que não incluiu o empreendedorismo social em sua análise da literatura sobre empreendedorismo sustentável. Estes autores afirmam que apesar de complementar, o empreendedorismo social tem um perfil e uma prática muito diferente do empreendedorismo ambiental, pois é focado principalmente em ONGs e outros tipos de organizações sem fins lucrativos, baseado em valores de seus empreendedores e tendo como alvo principalmente grupos sociais desfavorecidos.

De fato, ao contrário do lado ambiental, que é tratado principalmente como gerador de negócios a serem explorados, o lado social é considerado mais pelo aspecto da responsabilidade e motivação pessoal e organizacional do que como um nicho de negócios com potencial para gerar lucros. Mas existem tipos de empreendedorismo social cujo lucro é uma das, senão a principal, motivações dos empreendedores (SEELOS; MAIR, 2005). Os empreendedores que se enquadram nessa situação exploram principalmente oportunidades de negócio no segmento da saúde, da educação, do microcrédito e do comércio justo (HOCKERTS; WUSTENHAGEN, 2010), chamados aqui de negócios sociais.

BORGES, C.; BORGES, M. M.; FERREIRA, V. R. S.; NAJBERG, E.; TETE, M. F. Empreendedorismo Sustentável: Proposição De Uma Tipologia E Sugestões De Pesquisa. Revista de Empreendedorismo e Gestão de Pequenas Empresas, v. 2, n.1, p. 77-100, 2013. 
Para que essas oportunidades sociais ou ambientais sejam identificadas, Charter et al. (2002) defendem que as empresas construam um radar de sustentabilidade para detectar novas questões ambientais ou sociais. De acordo com Boszczowski e Teixeira (2009), o reconhecimento de oportunidades de negócios sustentáveis apresenta uma série de requisitos: i) inicialmente o empreendedor deve identificar uma necessidade sob a forma de uma causa ou problema social ou ambiental; ii) o empreendedor deve também identificar os meios de atender tal necessidade, ou seja, criar valor social e ambiental baseado na geração de valor econômico; iii) por último, ele precisa, cognitivamente, unir esses dois conhecimentos em um objeto coerente que pode então, ser chamado de oportunidade de negócios sustentáveis.

Para Gerlach (2000), a inovação sustentável em particular, torna-se bem sucedida quando empreendedores obtêm vantagens competitivas como, por exemplo, atingir sucesso econômico por meio da aplicação de práticas ambientais e sociais inovadoras. Contudo, tal sucesso será atingido somente se as tecnologias ou os produtos desenvolvidos possam se provar como alternativa sustentável viável e conquistar participação de mercado dos produtos convencionais (PUJARI; WRIGHT; PEATTIE, 2003).

Esse argumento é corroborado por Ginsberg e Bloom (2004). Eles advertem que os consumidores prefeririam escolher produtos ecologicamente corretos em detrimento de produtos menos amigáveis ao ambiente. Para esses autores, quando os consumidores são forçados a escolher entre os atributos do produto ou ajudar o ambiente, este último jamais ganha. Diante disso, o processo de desenvolvimento de novos produtos e serviços sustentáveis que conciliem sustentabilidade e atributos competitivos continua sendo um desafio para os empreendedores (MAXWELL; HORST, 2003; PUJARI, 2006; PACHECO; DEAN; PAYNE, 2010).

O empreendedorismo ambiental explora oportunidades em negócios ligados ao meio ambiente, enquanto que o empreendedorismo social explora negócios sociais. Essas duas possibilidades compõem o primeiro indicador considerado na tipologia aqui proposta: os negócios podem explorar o nicho ambiental ou social. $\mathrm{O}$

BORGES, C.; BORGES, M. M.; FERREIRA, V. R. S.; NAJBERG, E.; TETE, M. F. Empreendedorismo Sustentável: Proposição De Uma Tipologia E Sugestões De Pesquisa. Revista de Empreendedorismo e Gestão de Pequenas Empresas, v. 2, n.1, p. 77-100, 2013. 
segundo indicador está relacionado com a motivação para a incorporação da sustentabilidade, ou seja, se ela é o objetivo do empreendedor ao criar o negócio ou apenas um meio utilizado para realizar ganhos financeiros (PARRISH, 2010). O terceiro indicador trata da utilização ou não dos pressupostos da responsabilidade social empresarial na empresa nascente (DALMORO, 2009). O Quadro 1 indica quais são os indicadores e os tipos de empreendedorismo sustentáveis possíveis.

Quadro 1: Tipos de Empreendedorismo Sustentável.

\begin{tabular}{|l|l|}
\hline Indicador & Tipo \\
\hline Nicho da sustentabilidade explorado & $\begin{array}{l}\text { Negócio ambiental } \\
\text { Negócio social }\end{array}$ \\
\hline Papel da sustentabilidade & $\begin{array}{l}\text { Sustentabilidade como meio } \\
\text { Sustentabilidade como objetivo }\end{array}$ \\
\hline Uso da responsabilidade social empresarial & $\begin{array}{l}\text { Com responsabilidade social empresarial } \\
\text { Sem responsabilidade social empresarial }\end{array}$ \\
\hline
\end{tabular}

Fonte: Os Autores (2013)

Apesar de o Quadro 1 apresentar os tipos como estanques e exclusivos, é necessário considerar a possibilidade de haver negócios híbridos em que, por exemplo, um nicho social e ambiental é explorado conjuntamente. Cada um dos três indicadores considerados na tipologia será descrito nas próximas três seções do artigo.

\section{Nicho da Sustentabilidade Explorado: Ambiental ou Social}

Nessa seção serão apresentados os dois nichos de mercado tradicionalmente explorados por estes empreendedores sustentáveis: o ambiental e o social.

\section{Negócio Ambiental}

Escolhas de estilos de vida alternativos tais como autossuficiência, produção de alimentos orgânicos, movimentos de "slow food", reciclagem de resíduos pós- 
consumo e artesanato natural, são todos exemplos de oportunidades de negócios derivadas do nicho ambiental (HOLT, 2011). Esses exemplos de movimentos da sociedade representam várias iniciativas de produtores, consumidores ou cidadãos eco conscientes no sentido de internalizar, minimizar ou se antecipar às externalidades ambientais, o que resulta na introdução de uma nova categoria de produtos e serviços ecologicamente amigáveis (PASTAKIA, 2002).

Os negócios ambientais podem ser classificados em quatro categorias principais: (i) produtos eco eficientes; (ii) turismo e lazer na natureza; (iii) agricultura orgânica e extrativismo; e (iv) reciclagem e reutilização (LORDKIPANIDZE; BREZET; BACKMAN, 2005). Exemplos das quatro categorias são mostrados no Quadro 2.

Quadro 2: Categorias de Negócio Ambiental.

\begin{tabular}{|l|l|}
\hline Categorias & Exemplo \\
\hline Produtos eco eficientes & $\begin{array}{l}\text { Produtos mais eficientes energicamente ou } \\
\text { com baixo impacto ambiental, como a } \\
\text { fabricação e a instalação de equipamentos } \\
\text { de energia solar e de recuperadores de } \\
\text { calor, produção de móveis de bambu e } \\
\text { construção de casas ecológicas. }\end{array}$ \\
\hline Turismo e lazer na natureza & $\begin{array}{l}\text { Viagens, atividades, atrativos e pousadas } \\
\text { em ambientes naturais }\end{array}$ \\
\hline Reciclagem e reutilização & $\begin{array}{l}\text { Produção de alimentos orgânicos, } \\
\text { restaurante vegetariano, extrativismo de } \\
\text { produtos florestais, como a castanha, ervas } \\
\text { ou a madeira. }\end{array}$ \\
\hline
\end{tabular}

Fonte: Os Autores (2013)

Produtos, serviços e processos superiores que reduzem substancialmente os impactos ambientais e aumentam a qualidade de vida das pessoas é resultado de inovações sustentáveis desenvolvidas por empreendedores como parte central de

BORGES, C.; BORGES, M. M.; FERREIRA, V. R. S.; NAJBERG, E.; TETE, M. F. Empreendedorismo Sustentável: Proposição De Uma Tipologia E Sugestões De Pesquisa. Revista de Empreendedorismo e Gestão de Pequenas Empresas, v. 2, n.1, p. 77-100, 2013. 
suas atividades empresariais (SCHALTEGGER; WAGNER, 2011; SCHALTEGGER, 2002).

\section{Negócio Social}

Os negócios sociais podem ser classificados em quatro categorias principais: (i) produtos para grupos com necessidades especiais; (ii) microcrédito; (iii) comércio justo; e (iv) negócios na base da pirâmide (HOCKERTS; WUSTENHAGEN, 2010; PRAHALAD; HAMMOND, 2002; YUNUS, 2010). Exemplos das cinco categorias são dados no Quadro 3.

Quadro 3: Categorias de Negócio Social.

\begin{tabular}{|l|l|}
\hline Categorias & Exemplo \\
\hline especiais & $\begin{array}{l}\text { Produtos como foco em portadores de } \\
\text { necessidades especiais, como confecções } \\
\text { especializadas em roupas para cadeirantes } \\
\text { ou idosos. }\end{array}$ \\
\hline Microcrédito & $\begin{array}{l}\text { Grameen Bank, fundado por Muhammad } \\
\text { Yunus. }\end{array}$ \\
\hline Comércio justo & $\begin{array}{l}\text { Parceria entre produtores e consumidores } \\
\text { de café. }\end{array}$ \\
\hline Negócios na base da pirâmide & $\begin{array}{l}\text { Serviços de comunicação, como a telefonia, } \\
\text { ou bens de consumo, como alimentos, } \\
\text { ofertados de forma mais acessível para os } \\
\text { mais pobres. }\end{array}$ \\
\hline
\end{tabular}

Fonte: Os Autores (2013).

Das categorias apresentadas no Quadro 3, há um debate sobre a possibilidade de ser considerado um negócio social aquele que explora oportunidades de lucro geradas na base da pirâmide social. A premissa dos

BORGES, C.; BORGES, M. M.; FERREIRA, V. R. S.; NAJBERG, E.; TETE, M. F. Empreendedorismo Sustentável: Proposição De Uma Tipologia E Sugestões De Pesquisa. Revista de Empreendedorismo e Gestão de Pequenas Empresas, v. 2, n.1, p. 77-100, 2013. 
defensores desse segmento, conhecido como BOP - base of the pyramid (HART; CHRISTENSEN, 2002; PRAHALAD; HAMMOND, 2002; PRAHALAD; HART, 2002) é que focando nas pessoas mais pobres, ou seja, desenvolvendo ou oferecendo produtos e serviços que elas precisam, os empreendedores podem realizar lucros ao mesmo tempo em que atendem as necessidades e capacidades de consumo desse grupo, melhorando, dessa forma, suas condições de vida (HOCKERTS; WUSTENHAGEN, 2010). Este segmento do empreendedorismo social é o que tem seu caráter de sustentabilidade mais questionado, para alguns não podendo mesmo ser considerado uma forma de empreendedorismo social. Apesar disso, está aumentando sua inclusão e aceitabilidade como parte dos negócios sociais (HOCKERTS; WUSTENHAGEN, 2010).

\section{Papel da Sustentabilidade: Meio ou Objetivo}

As ações sustentáveis de cunho ambiental ou social, podem ser o meio ou o objetivo do empreendedor. Para uns, o objetivo principal com o empreendimento é o lucro, e a exploração de um negócio social ou ambiental é o meio utilizado para isso. Para outros, o objetivo é colaborar para o desenvolvimento sustentável, e o lucro proporcionado pelo negócio é apenas um meio de manter uma empresa e um estilo de vida compatíveis com os valores da sustentabilidade. Parrish (2010) distingue estes dois grupos de empreendedores sustentáveis como os que são movidos pela oportunidade (opportunity-driven) ou pela sustentabilidade (sustainable-driven). Os primeiros utilizam a sustentabilidade como meio, o segundo como objetivo.

Alguns pesquisadores como Patzelt e Shepherd (2010), só consideram empreendedores sustentáveis aqueles que são motivados por ganhos ambientais e sociais, além do financeiro. Nesse caso, um empreendedor que explora o nicho da sustentabilidade visando apenas o lucro, não seria considerado um empreendedor sustentável. Em contrapartida, Hockerts e Wustenhagen (2010) acreditam que os empreendedores que só exploram o nicho da sustentabilidade como meio também

BORGES, C.; BORGES, M. M.; FERREIRA, V. R. S.; NAJBERG, E.; TETE, M. F. Empreendedorismo Sustentável: Proposição De Uma Tipologia E Sugestões De Pesquisa. Revista de Empreendedorismo e Gestão de Pequenas Empresas, v. 2, n.1, p. 77-100, 2013. 
são considerados sustentáveis porque criam valor ambiental ou social graças ao produto ou serviço que oferecem.

\section{Empreender com ou Sem Responsabilidade Social Empresarial}

A evolução do pensamento e as práticas associadas à sustentabilidade discutidas no início desse artigo refletem-se no que hoje se entende por responsabilidade social e ambiental. Embora seja comum observar o uso individual desses termos para identificar visões, compromissos e práticas por parte de empresas, governo, terceiro setor ou indivíduos que envolvam tanto aspectos sociais como ambientais, é também comum o uso combinado dos termos, tais como: responsabilidade socioambiental, responsabilidade social e ambiental, responsabilidade social empresarial (RSE) com a mesma finalidade. Este último termo (RSE), foi o adotado na tipologia.

O fato de criar uma empresa com base em um produto ambiental ou social, não significa necessariamente que o empreendedor agirá com responsabilidade social e ambiental. Pode-se, por exemplo, vender placas de energia solar sem adotar práticas de responsabilidade social e ambiental. Mas o contrário também é possível: as empresas nascentes também podem adotar práticas de responsabilidade social empresarial (DALMORO, 2009; PIMENTEL; REINALDO; OLIVEIRA, 2010; RODGERS, 2010). Um empreendedor que vende placas de energia solar ao adotar em sua loja ações de reutilização e reciclagem dos papéis e da água utilizada, pratica a responsabilidade ambiental e, ao contratar apenas funcionários da comunidade próxima, a responsabilidade social.

A responsabilidade social empresarial é um elemento adicional importante na criação de valores (HOCKERTS; WUSTENHAGEN, 2010; HART; MILSTEIN, 2003). Nesse sentido, os empreendedores que desenvolvem um negócio ambiental ou social com suas respectivas responsabilidades estão criando ainda mais valores para a sociedade.

BORGES, C.; BORGES, M. M.; FERREIRA, V. R. S.; NAJBERG, E.; TETE, M. F. Empreendedorismo Sustentável: Proposição De Uma Tipologia E Sugestões De Pesquisa. Revista de Empreendedorismo e Gestão de Pequenas Empresas, v. 2, n.1, p. 77-100, 2013. 
Conforme afirmam Gomes e Moretti (2007), não há ainda uma compreensão comum sobre o que seja responsabilidade social e a mesma afirmação pode ser também estendida para a responsabilidade ambiental. Enquanto que para alguns "social" ou "ambiental" englobam ambos os aspectos, para outros há ainda uma compreensão de que o social se retrata mais às questões humanas, enquanto que o ambiental está associado às questões da natureza. Ou seja, uma visão que ainda mantém uma dicotomia anterior ao conceito de desenvolvimento sustentável.

Embora essa variabilidade na compreensão do termo responsabilidade social seja observada por vários autores (GOMES; MORETTI, 2007; DIAS, 2009), eles evidenciam que especialmente nas últimas décadas, a questão ambiental é uma das dimensões que pode ser considerada intrínseca ao termo responsabilidade social empresarial. Essa compreensão se reflete na definição do Instituto Ethos quando afirma:

[...] responsabilidade social empresarial é a forma de gestão que se define pela relação ética e transparente da empresa com todos os públicos com os quais ela se relaciona e pelo estabelecimento de metas empresariais que impulsionem o desenvolvimento sustentável da sociedade, preservando recursos ambientais e culturais para as gerações futuras, respeitando a diversidade e promovendo a redução das desigualdades sociais. (INSTITUTO ETHOS, 2011).

Com o objetivo de estimular a adesão a práticas de responsabilidade social de forma voluntária, o Instituto Ethos disponibiliza uma ferramenta online composta por uma série de indicadores para que empresas façam uma autoavaliação de suas práticas de responsabilidade social e se comparem com outras empresas. A ferramenta constitui-se em um questionário estruturado com os indicadores distribuídos em sete temas, sendo eles: (1) Valores, Transparência e Governança (Ex.: compromissos éticos, diálogo e engajamento das partes interessadas); (2) Público Interno (Ex.: gestão participativa, valorização da diversidade); (3) Meio Ambiente (Ex.: educação e conscientização ambiental, compromisso com a melhoria da qualidade ambiental); (4) Fornecedores (Ex.: critérios de seleção e avaliação de fornecedores); (5) Consumidores e Clientes (Ex.: excelência no atendimento); (6)

BORGES, C.; BORGES, M. M.; FERREIRA, V. R. S.; NAJBERG, E.; TETE, M. F. Empreendedorismo Sustentável: Proposição De Uma Tipologia E Sugestões De Pesquisa. Revista de Empreendedorismo e Gestão de Pequenas Empresas, v. 2, n.1, p. 77-100, 2013. 
Comunidade (relações com organizações locais) e (7) Governo e Sociedade (Ex.: participação em projetos sociais governamentais) (INSTITUO ETHOS, 2011).

Como remate é importante dizer que no dia $1^{\circ}$ de novembro de 2010, foi publicada em Genebra, na Suíça, a Norma Internacional ISO 26000 - Diretrizes sobre Responsabilidade Social. No Brasil, a versão em português da norma - a ABNT NBR ISO 26000 - foi lançada em 8 de dezembro do mesmo ano. Segundo a Norma ISO 26000 (INMETRO, 2011), a responsabilidade social de uma organização se expressa pelos impactos de suas decisões e atividades na sociedade e no ambiente, por meio de um comportamento ético e transparente que: contribua para o desenvolvimento sustentável; leve em consideração as expectativas das partes interessadas; esteja em conformidade com a legislação pertinente; esteja integrada em toda a organização.

\section{Considerações Finais e Sugestões para Pesquisa}

Este artigo propõe uma tipologia com diferentes categorias de empreendedorismo sustentável segundo a qual, podem-se encontrar empreendedores sustentáveis que exploram um negócio ambiental ou social, que empreendam negócios em que a sustentabilidade é o objetivo principal, ou ao contrário, apenas o meio de realizar ganhos financeiros, e que desenvolvem o novo negócio utilizando ou não os preceitos da responsabilidade social empresarial.

A prática da responsabilidade social empresarial pode tornar mais complexa a vida do empreendedor sustentável nascente. Ele terá que compor os custos e dificuldades de implementação desta responsabilidade em um mercado que, apesar de receptivo aos produtos ambientais e sociais, prefere quase sempre produtos mais baratos ou que agreguem outros atributos. Alguns produtos verdes exigem recursos e tecnologias que o inviabilizam comercialmente (PACHECO; DEAN; PAYNE, 2010). Daí a necessidade de estudar o desenvolvimento de produtos que conciliem sustentabilidade e competitividade (HALL; DANEKE; LENOX, 2010; MAXWELL; HORST, 2003; PUJARI, 2006).

BORGES, C.; BORGES, M. M.; FERREIRA, V. R. S.; NAJBERG, E.; TETE, M. F. Empreendedorismo Sustentável: Proposição De Uma Tipologia E Sugestões De Pesquisa. Revista de Empreendedorismo e Gestão de Pequenas Empresas, v. 2, n.1, p. 77-100, 2013. 
O conhecimento no campo do empreendedorismo foi construído essencialmente tendo como base a lógica tradicional do mundo dos negócios, em que se busca o crescimento sem se preocupar com os impactos sociais e ambientais, sendo pouco exploradas as particularidades do empreendedorismo sustentável (DEAN; MCMULLEN, 2007). Como são criadas as empresas que já nascem com a cultura da sustentabilidade? Quais são os obstáculos que os empreendedores sustentáveis enfrentam? Quais são os fatores de sucesso na criação de novas empresas sustentáveis? Essas são algumas das questões que empreendedores e pessoas atuantes no sistema de apoio aos empreendedores se deparam e para as quais as respostas na literatura ainda são insuficientes.

Há uma série de particularidades no processo empreendedor sustentável que precisam ser exploradas em novos estudos, independente da motivação do empreendedor (se para ele a sustentabilidade é meio ou objetivo), do nicho explorado (ambiental ou social) e se sua ação é realizada com ou sem responsabilidade social. Há indícios de que os empreendedores sustentáveis têm similaridades, mas também divergem dos empreendedores tradicionais em termos de traços de personalidade, objetivos e fontes de motivação (KIRKWOOD; WALTON, 2010; VEGA; KIDWELL, 2007; MAXWELL; HORST, 2003; PUJARI, 2006). E que os empreendedores movidos pela sustentabilidade têm um processo de criação diferente dos movidos pelo lucro, com mais envolvimento dos stakeholders e mais próximos de exercer a responsabilidade social e ambiental (PARRISH, 2010). Tudo isso carece de mais investigação empírica.

Outro ponto que precisa ser considerado em pesquisas futuras é a diversificação das variáveis dependentes do empreendedorismo. Elas precisam ir além das preocupações financeiras, que normalmente são as consideradas, e incorporar elementos de sustentabilidade. Fica difícil falar em sustentabilidade sem incorporar nas pesquisas uma gama mais ampla de consequências da ação empreendedora (COHEN, SMITH; MITCHELL, 2008)

Finalmente, poucas são as pesquisas em empreendedorismo sustentável que investigam e exploram negócios sociais e ambientais de forma integrada. Em geral,

BORGES, C.; BORGES, M. M.; FERREIRA, V. R. S.; NAJBERG, E.; TETE, M. F. Empreendedorismo Sustentável: Proposição De Uma Tipologia E Sugestões De Pesquisa. Revista de Empreendedorismo e Gestão de Pequenas Empresas, v. 2, n.1, p. 77-100, 2013. 
estão analisando casos de empresas que exploraram um ou outro nicho da sustentabilidade (PATZEL; SHEPHERD, 2010). Futuras pesquisas também podem investigar a aplicação da tipologia proposta no contexto do empreendedorismo corporativo sustentável (ISAAK, 2002; MILES; MUNILLA; DARROCH, 2009; HOCKERTS; WUSTENHAGEN, 2010). Apesar de o empreendedorismo corporativo não ter feito parte do escopo do presente artigo, os indicadores utilizados na tipologia proposta parecem servir também para o empreendedorismo corporativo sustentável.

Questões como essas só poderão ser respondidas com lentes disciplinares e teóricas variadas. Do campo do empreendedorismo pode-se utilizar, entre outros, a efetuação (SARASVATHY, 2001), a descoberta e a criação de oportunidades (SHANE; VENKATARAMAN, 2000), a bricolagem (BAKER; NELSON, 2005), o marketing empreendedor (CHARTER et al., 2002; COLLINSON; SHAW, 2001; MORRIS, SCHINDEHUTTE; LAFORGE, 2002), os modelos de criação de novos negócios com ênfase no processo (BHAVE, 1994) e os aspectos culturais e institucionais (O'NEILL; HERSHAUER; GOLDEN, 2009; MEEK; PACHECO; YORK, 2010).

Agradecimentos:

Conselho Nacional de Desenvolvimento Científico e Tecnológico

\section{Referências}

ALLEN, J.; MALIN, S. Green entrepreneurship: a method for managing natural resources. Society and Natural Resources, v. 21, p. 828-844, 2008.

BAKER, T.; NELSON, R. Creating something from nothing: resource construction through entrepreneurial bricolage. Administrative Science Quarterly, v. 50, p. 329366, 2005.

BORGES, C.; BORGES, M. M.; FERREIRA, V. R. S.; NAJBERG, E.; TETE, M. F. Empreendedorismo Sustentável: Proposição De Uma Tipologia E Sugestões De Pesquisa. Revista de Empreendedorismo e Gestão de Pequenas Empresas, v. 2, n.1, p. 77-100, 2013. 
BARBIERE, J. C.; SIMANTON, M. A. Organizações inovadoras sustentáveis. São Paulo: Atlas, 2007.

BENNETT, S. Ecopreneuring: the complete guide to small business opportunities from the environmental revolution. New York: Wiley, 1991.

BHAVE, M. P. A process model of entrepreneurial venture creation. Journal of Business Venturing, v. 9, n.3, p. 223-242, 1994.

BOSZCZOWSKI, A. K.; TEIXEIRA, R. O empreendedorismo sustentável e o processo empreendedor: em busca de oportunidades de novos negócios como solução para problemas sociais e ambientais. In: ENCONTRO NACIONAL DA ASSOCIAÇÃO NACIONAL DE PÓS-GRADUAÇÃO E PESQUISA EM ADMINISTRAÇÃO, 33, 2009, São Paulo. Anais...Rio de Janeiro: ANPAD, 2009.

BRASIL. INMETRO. Ministério do Desenvolvimento, Indústria e Comércio Exterior. Desenvolvimento Sustentável. Disponível em: $<$ http://www.inmetro.gov.br/qualidade/responsabilidade_social/index.asp>. Acesso em: 20 abr. 2011.

BRUIN, A.; BRUSH, C. G.; WELTER, F. Advancing a framework for coherent research on women's entrepreneurship. Entrepreneurship: Theory \& Practice, v. 31, n. 3, p. 323-339, 2007.

CHARTER, M. et al. Marketing and sustainability. Sustainable Marketing Knowledge Network. London, 2002.

COHEN, B.; SMITH, B.; MITCHELL, R. Toward a sustainable conceptualization of dependent variables in entrepreneurship research. Business Strategy and the Environment, v. 17, n. 2, p. 107-119, 2008.

BORGES, C.; BORGES, M. M.; FERREIRA, V. R. S.; NAJBERG, E.; TETE, M. F. Empreendedorismo Sustentável: Proposição De Uma Tipologia E Sugestões De Pesquisa. Revista de Empreendedorismo e Gestão de Pequenas Empresas, v. 2, n.1, p. 77-100, 2013. 
COHEN, B.; WINN, M. I. Market imperfections, opportunity and sustainable entrepreneurship. Journal of Business Venturing, v. 22, n. 1, p. 29-49, 2007.

COLLINSON, E.; SHAW, E. Entrepreneurial marketing: a historical perspective on development and practice. Management Decision, v. 39, n. 9, p. 761-766, 2001.

DALMORO, M. A visão da sustentabilidade na atividade empreendedora: uma análise a partir de empresas incubadas. Revista Gestão Organizacional, v. 2, n. 1, p. 87-104, 2009.

DEAN, T.; MCMULLEN, J. Toward a theory of sustainable entrepreneurship: reducing environmental degradation through entrepreneurial action. Journal of Business Venturing, v. 22, n. 1, p. 50-76, 2007.

DESS, G. D. et al. Emerging issues in corporate entrepreneurship. Journal of Management, v. 29, n. 3, p. 351-378, 2003.

DIAS, R. Gestão Ambiental: responsabilidade social e sustentabilidade. São Paulo: Atlas, 2009.

GARTNER, W. B. A conceptual framework for describing the phenomenon of new venture creation. Academy of Management Review, v. 10, n. 4, p. 696-706, 1985.

GERLACH, A. Sustainable entrepreneurship and innovation. Centre for Sustainability Management: University of Lüneberg. Lüneberg, Germany. 2000.

GIBBS, D. Sustainability entrepreneurs, ecopreneurs and the development of a sustainable economy. Greener Management International, v. 55, p. 63-78, 2009.

BORGES, C.; BORGES, M. M.; FERREIRA, V. R. S.; NAJBERG, E.; TETE, M. F. Empreendedorismo Sustentável: Proposição De Uma Tipologia E Sugestões De Pesquisa. Revista de Empreendedorismo e Gestão de Pequenas Empresas, v. 2, n.1, p. 77-100, 2013. 
GINSBERG, J. M.; BLOOM, P. N. Choosing the right green marketing strategy. MIT Sloan Management Review, p. 79-84, 2004.

GOMES, A.; MORETTI, S. A responsabilidade social: uma discussão sobre o papel das empresas. São Paulo: Saraiva, 2007.

HALL, J. K.; DANEKE, G. A.; LENOX, M. J. Sustainable development and entrepreneurship: past contributions and future directions. Journal of Business Venturing, v. 25, p. 439-448, 2010.

HART, S. L.; CHRISTENSEN, C. M. The great leap: driving innovation from the base of the pyramid. Mit Sloan Management Review, v. 44, p. 49-56, 2002.

HART, S. L.; MILSTEIN, M. B. Creating sustainable value. Academy of Management Executive, v. 17, n. 2, p. 56-67, 2003.

HOCKERTS, K.; WÜSTENHAGEN, R. Greening Goliaths versus emerging Davids: theorizing about the role of incumbents and new entrants in sustainable entrepreneurship. Journal of Business Venturing, v. 25, p. 481-492, 2010.

HOLT, D. Where are they now? Tracking the longitudinal evolution of environmental businesses from the 1990s. Business Strategy and the Environment, v. 20, n. 4, p. 238-250, 2011.

INSTITUTO ETHOS. O que é RSE? Disponível em: <http://www.ethos.org.br>. Acesso em: 20 abr. 2011.

ISAAK, R. The making of the ecopreneur. Greener Management International, v. 38, p. 81-92, 2002.

BORGES, C.; BORGES, M. M.; FERREIRA, V. R. S.; NAJBERG, E.; TETE, M. F. Empreendedorismo Sustentável: Proposição De Uma Tipologia E Sugestões De Pesquisa. Revista de Empreendedorismo e Gestão de Pequenas Empresas, v. 2, n.1, p. 77-100, 2013. 
KIRKWOOD, J.; WALTON, S. What motivates ecopreneurs to start businesses? International Journal of Entrepreneurial Behaviour \& Research, v. 16, n. 3, p. 204-228, 2010.

KUCKERTZ, A.; WAGNER, M. The influence of sustainability orientation on entrepreneurial intentions: investigating the role of business experience. Journal of Business Venturing, v. 25, p. 524-539, 2010.

LARSON, A. L. Sustainable innovation through an entrepreneurship lens. Business Strategy and the Environment, v. 9, p. 304-317, 2000.

LAWRENCE, A.; WEBER, J.; POST, J. Business and society. New York: McGrawHill, 2005.

LORDKIPANIDZE, M.; BREZET, H.; BACKMAN, M. The entrepreneurship factor in sustainable tourism development. Journal of Cleaner Production, v. 13, p. 787798, 2005.

MACHADO, $H$. et al. $O$ processo de criação de empresas por mulheres. RAE electronica. v. 2, n. 2. 2003. Disponível em: <http://www.scielo.br/pdf/raeel/v2n2/v2n2a07.pdf>. Acesso em: 26 abr. 2011.

MAXWELL, D.; HORST, R. V. Developing sustainable products and services. Journal of Cleaner Production, v. 11, p. 883-895, 2003.

MEEK, W. R., PACHECO, D. F. YORK, J. G. The impact of social norms on entrepreneurial action: evidence from the environmental entrepreneurship context. Journal of Business Venturing, v. 25, p. 493-509, 2010. 
MENON Anil, MENON, Ajay. Enviropreneurial marketing strategy: the emergence of corporate environmentalism as marketing strategy. Journal of Marketing, v. 61, p. 51-67, 1997.

MILES, M. P., MUNILLA, L. S., DARROCH, J. Sustainable corporate entrepreneurship. International Entrepreneurship Management Journal, v. 5, n. 1, p. 65-76, 2009.

MILES, R. E.; SNOW, C. C. Organizations: new concepts for new forms. California Management Review, v. 28, n. 3, p. 62-73, 1986.

MILLER, D. Configuration revisited. Strategic Management Journal, v. 17, n. 7, p. 502-512, 1996.

MORRIS, M. H.; SCHINDEHUTTE, M.; LAFORGE, R. W. Entrepreneurial marketing: a construct for integrating emerging entrepreneurship and marketing perspectives. Journal of Marketing Theory and Practice, v. 10, n. 4, p. 11-18, 2002.

O'NEILL, G. D.; HERSHAUER, J. C.; GOLDEN, J. S. The cultural context of sustainability entrepreneurship. Greener Management International, v. 55, p. 3346, 2009.

PACHECO, D. F.; DEAN, T. J.; PAYNE, D. S. Escaping the green prison: entrepreneurship and the creation of opportunities for sustainable development. Journal of Business Venturing, v. 25, p. 464-480, 2010.

PARRISH, B. D. Sustainability-driven entrepreneurship: principles of organization design. Journal of Business Venturing, v. 25, p. 510-523, 2010.

BORGES, C.; BORGES, M. M.; FERREIRA, V. R. S.; NAJBERG, E.; TETE, M. F. Empreendedorismo Sustentável: Proposição De Uma Tipologia E Sugestões De Pesquisa. Revista de Empreendedorismo e Gestão de Pequenas Empresas, v. 2, n.1, p. 77-100, 2013. 
PARRISH, B. D.; FOXON, T. J. Sustainability entrepreneurship and equitable transitions to a low-carbon economy. Greener Management International, v. 55, p. 47-62, 2009.

PASTAKIA, A. Assessing ecopreneurship in the context of a developing country: the case of India. Greener Management International, v. 38, p. 93-108, 2002.

PATZELT, H., SHEPHERD, D. A. Recognizing opportunities for sustainable development. Entrepreneurship: Theory \& Practice, p. 631-652, 2011. Doi: 10.1111/j.1540-6520.2010.00386.x

PIMENTEL, T.; REINALDO, H.; OLIVEIRA, L. Empreendedorismo Sustentável: uma análise da implementação da sustentabilidade empresarial em micro, pequenas e médias empresas industriais atendidas pelo PEIEX. In: SIMPÓSIO DE ADMINISTRAÇÃO DA PRODUÇÃO, LOGÍSTICA E OPERAÇÕES INTERNACIONAIS, 13., 2010, São Paulo. Anais... São Paulo, 2010.

PIRNAY, F. ; SURLEMONT, B. ; NLEMVO, F. Toward a typology of university spinoffs. Small Business Economics, v. 21, n. 4, p. 355-369, 2003.

PRAHALAD, C. K.; HAMMOND, A. Serving the world's poor, profitably. Harvard Business Review, v. 80, n. 9, p. 48-57, 2002.

PRAHALAD, C. K.; HART, S. L. The fortune at the bottom of the pyramid. Business and Strategy, V. 26, p. 2-14, 2002.

PUJARI, D. Eco-innovation and new product development: understanding the influences on market performance. Technovation, v. 26, p. 76-85, 2006.

BORGES, C.; BORGES, M. M.; FERREIRA, V. R. S.; NAJBERG, E.; TETE, M. F. Empreendedorismo Sustentável: Proposição De Uma Tipologia E Sugestões De Pesquisa. Revista de Empreendedorismo e Gestão de Pequenas Empresas, v. 2, n.1, p. 77-100, 2013. 
PUJARI, D.; WRIGHT, G.; PEATTIE, K. Green and competitive: influences on environmental new product development performance. Journal of Business Research, v. 56, n. 8, p. 657-671, 2003.

RODGERS, C. Sustainable entrepreneurship in SMEs: a case study analysis. Corporate Social Responsibility and Environmental Management, v. 17, p. 125132, 2010.

SACHS, I. Estratégias de transição para o século XXI. In: BURSZTYN, M. (Org.). Para pensar o desenvolvimento sustentável. São Paulo: Brasiliense, 1994. p. 2956.

SARASVATHY, S. D. Causation and effectuation: toward a theoretical shift from economic inevitability to entrepreneurial contingency. Academy of Management Review, v. 26, n. 2, p. 243-263, 2001.

SCHALTEGGER, S. A framework for ecopreneurship: leading bioneers and environmental managers to ecopreneurship. Greener Management International, v. 38, p. 45-58, 2002.

SCHALTEGGER, S.; WAGNER, M. Sustainable entrepreneurship and sustainability innovation: categories and interactions. Business Strategy and the Environment, v. 20, n. 4 , p. 222-237, 2011.

SCHAPER, M. The essence of ecopreneurship. Greener Management International, v. 38 (Summer), p. 26-30, 2002.

SCHUMPETER, J. The theory of economic development. Cambridge: Harvard University Press, 1934.

BORGES, C.; BORGES, M. M.; FERREIRA, V. R. S.; NAJBERG, E.; TETE, M. F. Empreendedorismo Sustentável: Proposição De Uma Tipologia E Sugestões De Pesquisa. Revista de Empreendedorismo e Gestão de Pequenas Empresas, v. 2, n.1, p. 77-100, 2013. 
SCOTTO, G.; CARVALHO, I. C. M.; GUIMARÃES, L. B. Desenvolvimento sustentável. Petrópolis: Vozes, 2007.

SEELOS, C.; MAIR, J. Social entrepreneurship: creating new business models to serve the poor. Business Horizons, v. 48, n. 3, p. 241-246, 2005.

SHANE, S. Technological opportunities and new firm creation. Management Science, v. 47, n. 2, p. 205-220, 2001.

SHANE, S.; VENKATARAMAN, S. The promise of entrepreneurship as a field of research. Academy of Management Review, v. 25, p. 217-226, 2000.

SHEPHERD, D. A.; PATZELT, H. The new field of sustainable entrepreneurship: studying entrepreneurial action linking "what is to be sustained" with "what is to be developed". Entrepreneurship: Theory \& Practice, v. 35, n. 1 (January), p. 137-163, 2011.

VEGA, G.; KIDWELL, R. E. Toward a typology of new venture creators: similarities and contrasts between business and social entrepreneurs. New England Journal of Entrepreneurship, v. 10, n. 2, p. 15-29, 2007.

WORLD WIDE FUND FOR NATURE. Low carbon jobs for Europe. London. 2009

YUNUS, M. Criando um negócio social. Rio de Janeiro: Campus, 2010.

ZAHRA, S. et al. A typology of social entrepreneurs: motives, search processes and ethical challenges. Journal of Business Venturing, v. 24, n. 6, p. 519-532, 2009.

Artigo recebido em 11/03/2013. Aprovado em 30/04/2013.

BORGES, C.; BORGES, M. M.; FERREIRA, V. R. S.; NAJBERG, E.; TETE, M. F. Empreendedorismo Sustentável: Proposição De Uma Tipologia E Sugestões De Pesquisa. Revista de Empreendedorismo e Gestão de Pequenas Empresas, v. 2, n.1, p. 77-100, 2013. 